\title{
To reattach or not to reattach, that is not the question
}

In 1986, Crawford and colleagues ${ }^{1}$ noted that intercostal artery (ICA) reattachment was associated with an increased incidence of paraplegia after thoracoabdominal aortic aneurysm replacement. Subsequently, Safi and associates ${ }^{2}$ noted that during the Crawford group's "clamp and sew" era, the crossclamp time was a greater determinant of paraplegia than was ICA reattachment, as the added suturing became detrimental. With use of the adjuncts distal aortic perfusion and cerebrospinal fluid drainage, Safi and associates ${ }^{2}$ observed a reduction in immediate paraplegia with the reattachment of ICAs, specifically: T8 to T12. In contrast, Griepp's experimental and clinical work on the "collateral network" minimized the importance of ICA reattachment by promoting the collateralization of spinal cord perfusion. ${ }^{3}$ Moreover, development of this network likely occurred within 1 week, reducing any need for a long-term conduit patency. These competing models led to continued controversy, especially as the endovascular revolution began.

As outcomes improved with open thoracoabdominal aortic aneurysm repair and adjuncts reduced the risks of immediate paraplegia, delayed paraplegia became more significant. Recent work from my group demonstrated the importance of adequate, stable systolic arterial blood pressure, as opposed to mean arterial blood pressure, as well as the importance of the reattachment of patent ICAs for the prevention of delayed paraplegia. ${ }^{4,5}$ Although still subject to debate, whether to reattach is not the question-as we believe this has been answered. The questions that remain are how do we reattach, what conduit do we use, and does all this really matter?

In their study reported in this issue of the Journal, Sultan and colleagues ${ }^{6}$ performed endoscopic harvest of the greater saphenous vein as the conduit for reattachment of selected ICAs for the prevention of paraplegia. Their series included 22 cases of thoracoabdominal aortic aneurysm repair (of which 12 cases were extent II), with individual bypasses of as many as 3 patent ICAs per patient. The technique appears cumbersome and tedious, because the greater

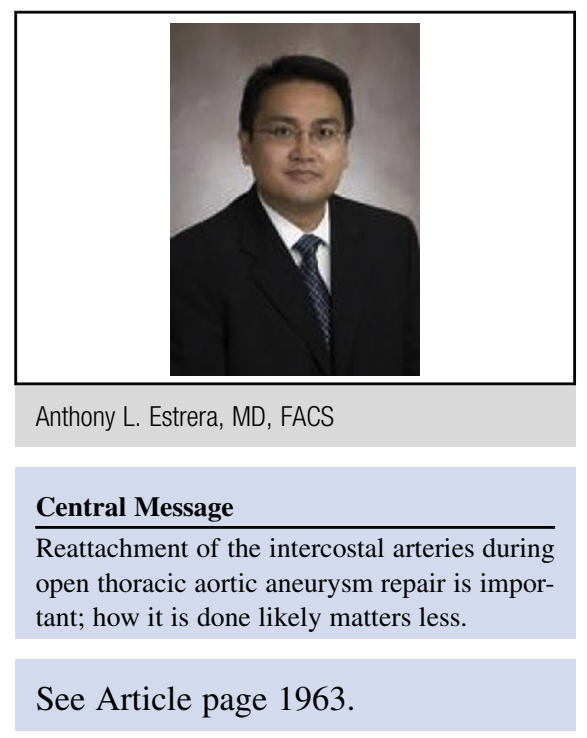

saphenous vein has to be harvested and prepared before the aortic repair-and individual bypasses to each selected patent ICA have to be performed as man as 3 times after completion of the aortic replacement. The results are commendable, as there were no deaths or cases of permanent paraplegia. Although completeness of follow-up was not mentioned, $72 \%$ of the saphenous vein graft ICA bypasses were patent. Sultan and colleagues ${ }^{6}$ reported interrogation of ICA saphenous vein grafts with transit-time flowmetry, but they did not report whether this changed their intraoperative management or if reduced flow predicted early or late thrombosis. They also did not note why only 2 ICA bypasses per patient were performed.

Sultan and colleagues ${ }^{6}$ are to be commended for reporting a relatively novel approach to ICA reattachment in human patients (although Lansman and Spielvogel reported using SVG for ICA in pig models) and demonstrating persistent patency. Unfortunately, definitive conclusions cannot be derived from this report because of the limited cohort size; inherent biases, such as, to name a few, which ICA to reattach (upper or lower, left or right); when to reattach in relation to the neural monitoring; and the hemodynamic parameters. Long-term follow-up of this series is encouraged, because previous ICA reattachment techniques, such as the traditional island patch (which was subject to aneurysmal degeneration) and the direct Dacron polyester fabric graft bypass (which was subject to late thrombosis) had limitations.

In the end, spinal cord protection is achieved by providing perfusion directly with reattachment of ICAs and indirectly by increasing hemodynamics (systolic 
arterial blood pressure) to promote early collateralization of the spinal cord blood supply. Whether to reattach has likely been answered. How to do it and what conduit to use, likely does not matter.

\section{References}

1. Crawford ES, Crawford JL, Safi HJ, Coselli JS, Hess KR, Brooks B, et al. Thoracoabdominal aortic aneurysms: preoperative and intraoperative factors determining immediate and long-term results of operations in 605 patients. J Vasc Surg. 1986:3:389-404.

2. Safi HJ, Miller CC III, Carr C, Iliopoulos DC, Dorsay DA, Baldwin JC. Importance of intercostal artery reattachment during thoracoabdominal aortic aneurysm repair. J Vasc Surg. 1998;27:58-66; discussion 66-8.
3. Etz CD, Kari FA, Mueller CS, Silovitz D, Brenner RM, Lin HM, et al. The collat eral network concept: a reassessment of the anatomy of spinal cord perfusion. $J$ Thorac Cardiovasc Surg. 2011;141:1020-8.

4. Sandhu HK, Evans JD, Tanaka A, Atay S, Afifi RO, Charlton-Ouw KM, et al. Fluctuations in spinal cord perfusion pressure: a harbinger of delayed paraplegia after thoracoabdominal aortic repair. Semin Thorac Cardiovasc Surg. 2017;29: 451-9.

5. Afifi RO, Sandhu HK, Zaidi ST, Trinh E, Tanaka A, Miller CC III et al. Intercostal artery management in thoracoabdominal aortic surgery: to reattach or not to reattach? J Thorac Cardiovasc Surg. 2018;155: 1372-8.e1.

6. Sultan I, Dufendach K, Cardounel A, Navid F, Gleason TG. Intercoastal artery reimplantation with saphenous vein during thoracoabdominal aortic replacement. J Thorac Cardiovasc Surg. 2018;155: 1963-5. 